\title{
Spatial re- organization of the contemporary hospital design
}

\author{
Karaoulanis Andreas, MBA, MscEng \\ andrekaraoul@gmail.com
}

\section{ABSTRACT}

This short paper is describing in brief the need that developed the last years for a radical change in hospitals' spatial structure in order to help both patients and the staff to have mutual gains. Contemporary hospitals are in need of structural changes due to several political, economic, social paragons as well as due to technological advances and progress in medical science. It is the author's goal to provide the guidelines that need to be followed in order several potential changes in terms of spatial re- organization to be achieved.

\section{Key- words}

Hospitals; Space management; Architectural; health; safety.

\section{Academic Discipline and Sub Disciplines}

Management; Social Sciences; Architecture

\section{Type (Method/Approach)}

Literary Analysis

\section{Council for Innovative Research}

Peer Review Research Publishing System

Journal: International Journal Of Management \& Information Technology

Vol . 10, No 9

editorsijmit@gmail.com

www.ijmit.com 


\section{ISSN 2278-5612}

\section{INTRODUCTION}

Building a contemporary hospital can be a very challenging/ intriguing procedure for engineers, especially nowadays due to the rapid changes in needs and technical alterations in terms of surgical, medical and general hospital advances.

\section{HOSPITAL DESIGN}

The importance of the proper design of contemporary hospitals and the introductionof a new pioneer design approach in order to help the medical staff to operate in a more efficient way, can mainly rely upon the following requirements:

$\checkmark$ Minimizing distance of necessary in- hospital travelling between frequently used medical areas,

$\checkmark$ Subvene medical supervision of in- patients, especially when staff is limited/ insufficient,

$\checkmark \quad$ Careful pre- design programming in order to use only needed spaces. In addition, an efficient use of space in order to locate support spaces so that they may be shared by adjacent functional areas, and by making prudent use of multi- purpose spaces. Also, Group or combine functional areas with similar system requirements,

$\checkmark$ Provision of an efficient logistics system which will contribute in the best possible way in handling and using of elevators, box conveyors, manual or automated carts, and gravity or pneumatic chutes, efficient handling of food and clean supplies and the removal of waste, recyclables, and soiled material,

$\checkmark$ Consolidate outpatient functions for more efficient operation-on first floor, if possible-for direct access by outpatients,

$\checkmark \quad$ "Provide optimal functional adjacencies, such as locating the surgical intensive care unit adjacent to the operating suite. These adjacencies should be based on a detailed functional program which describes the hospital's intended operations from the standpoint of patients, staff, and supplies" (wbdg.org, 2011).

\section{HOSPITAL SPACE MANAGEMENT}

As space management is one of the most important elements that can be the foundation of the proper organization's run (Yusof M., 2013), it can also be particularly important for hospitals, due to the continuous increase in in patient needs, something which is the result of several paragons such as technological improvements, demography, new medical methods or approaches, political changes, economic influences, human needs etc. (Heng et al., cited in Yusof M., 2013).

In terms of space management, several other parameters should be examined, such as:

$\checkmark \quad$ Space of inpatient units, which over the years has exceeded expectancies, something which usually results in severe lack of space. This fact per se requires immediate attention and a more effective space design in accordance to the existent spatial hospital's configuration,

$\checkmark$ As Ambulatory care and surgeries have replaced, in almost global scale the last years, the emergency department (ED) as a feeder to the hospital, the ED has become an area of specialized care, including increasingly specific requirements for trauma. In addition, the need to respond flexibly to a range of patient care demands has caused many institutions to use a single-room model that has become larger because of increased clearance criteria. Such changes have resulted in the need of a different spatial planning which can also result to a more ergonomic design of the whole patient care faculty design in hospital scale,

$\checkmark$ As the last advances in imaging technology and the increasing number of modalities have caused radiology departments to become very complicated areas, several issues arose in terms of operational relationships, such as proximity to the imaging department and in-suite or in-room surgical imaging. Easily can be understood from the above that technological advances have resulted in increased space demands for the equipment and the need for careful sub- departmental boundaries driven by patient safety protocols (O' Neil YT. J., 2014).

In addition, other parameters that should be examined, are the following:

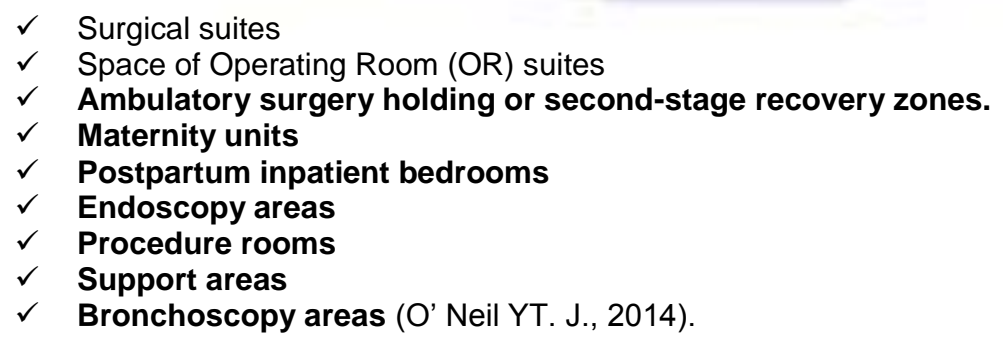

A very important of the in- hospital space management function is the "materials management group" (Little et al., 2008) According to Little et al. (2008), the materials management group is usually held responsible for the implementation of a good service in delivering products according to the inventory policies of the hospital in question. This function is very important for the overall hospital function, especially when important alterations will occur in the hospital's infrastructure, function and size. In such occasions, the group requires that the above mentioned policies in terms i.e. of products' delivery should be reviewed and be prepared in order to act in accordance with the new hospital infrastructure. 


\section{HOSPITAL SPACE PLANNING}

Hospital space planning, as any other kind of building space planning, is based upon several pillars which are the main processing procedure for the whole planning, although we need to be more careful in terms of some specific parameters like the space allocation which is very crucial when we come to hospitals.

In terms of space planning processes, the following increments of work are usually used (Addi G., et al., 2000):

$\checkmark$ Programming, which includes a space survey, which consists of an inventory of existing (or proposed) equipment and furniture, interviews with clients and users, and other data collection tools. The information that will be gathered by the conclusion of this stage will be compiled and analyzed in order to help the authors to be able to determine the range of functions that must take place.

$\checkmark$ Preliminary diagramming. During this stage, the authors will try to determine the estimated area of the approximate square footage needed for each function and/or space. This will be followed by a spatial positioning and relationships that may be illustrated by bubble and adjacency diagrams. In this way, architects can depict via several blocking plans (overlaid on the building core and shell plan), and indicate horizontal boundaries of major functional areas and circulation patterns for each figure. Diagrams and plans will help to demonstrate how functions are placed on each available level.

$\checkmark \quad$ Space plans and furniture plans. The documents for the space planning will be developed in a way that they will include space plans for the interior and schematic furniture plans. The interior construction and structural requirements also will be a vital part of the space planning documentation.

The above mentioned stages/ documents/ plans are the foundation upon which the whole re- plan and hospital design should be based.

\section{Space planning correlation to in- patients' health and safety}

It is very important to underline that space planning not only have vast impact in safety, and health of the in- patients, but can affect the health care personnel's performance, thus the way health care is provided (Race M.C., 2012). Factors such as space, lighting, use of color, acoustics, noise levels, smells and the degree of control a patient has over their environment, which according to Race M.C. (2012), can be very important factors which can influence in different ways both patients and medical staff, so much be taken under vast consideration in the hospitals' design.

According to Dresler et al. (2015), improvements in the structural environment of the hospital can trigger several positive reactions from the patients in terms of their health improvement. The architectural changes can influence coersive measures via mediators such as the following:

$\checkmark \quad$ Increased patients' well being

$\checkmark \quad$ Improved staff- patient relationship

$\checkmark$ More opportunities for patients to withdraw from stressful situations (Dresler et al., 2015).

According to Kong et al. (2013), patient proximity can facilitate the transmission of Methicillin Resistant Staphylococcus Aureus (MRSA), something which underlines the importance of hospital spatial arrangements of beds, cubicles and wards in understanding MRSA transmission risk. As such an issue is a very important paragon in terms of patients' health, identifying high-risk areas of transmission may be useful in the design of more effective, targeted MRSA interventions (Kong et al., 2013).

\section{CONCLUSIONS}

Hospitals worldwide nowadays are facing several challenges due to politico-economic situations, technological and medical advances etc. In such an environment which changes rapidly a very important factor is the re- construction/ design of hospitals in terms of spatial design. This is very important as can have vast impact in patients' safety and health, in staffs' performance and in the overall performance of the hospital in terms of medical care.

\section{REFERENCES}

[1] Addi G; Lytle J., 2000. Space Planning. Space Planning. [pdf]. American Insitute of Architechts. USA. Available at: $<$ www.aia.org/aiaucmp/groups/aia/documents/pdf/aiab089276.pdf. [Accesed 13 November 2015].

[2] Dresler, T., Rohe, T., Weber, M., Strittmatter, T. \&Fallgatter, A.J. 2015, "Effects of improved hospital architecture on coercive measures", World Psychiatry, vol. 14, no. 1, pp. 105-106.

[2] Kong F.; Paterson D.; Whitby M.; Coory M.; Clements CA A., A hierarchical spatial modelling approach to investigate MRSA transmission in a tertiary hospital. BMC Infectious Diseases. Vol.13 (449).

[3] Little, J. \& Coughlan, B. 2008, "Optimal inventory policy within hospital space constraints", Health Care Management Science, vol. 11, no. 2, pp. 177-183.

[4] O' Neil T.J., 2014. Sizeable Differences. How regulations and technologies influence space planning. Health Facilities Management [online]. Available ht: http://www.hfmmagazine.com/display/HFM-newsarticle.dhtml?dcrPath=/templatedata/HF_Common/NewsArticle/data/HFM/Magazine/2014/Mar/0314HFM_FEA_design

[Accessed 14 November 2015]. 


\section{ISSN 2278-5612}

[5] Race M.C., 2012. If hospital environment affect patients, what about their impact on staff? The Guardian [online]. Available at: <http://www.theguardian.com/sustainable-business/hospital-environment-affect-patients-staff> [Accessed 14 November 2015].

[6] Wbdg.org, 2011. Hospital, Overview [online]. Available at: <https://www.wbdg.org/design/hospital.php> [Accessed 15 November 2015].

[7] Yusof M., 2013. The strategies of ward space and equipment management in hospital when patient overload occurs. International Journal of Facility Management, Vol. 4 (1).

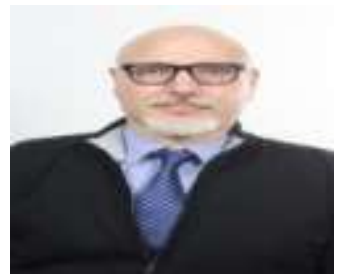

Andreas Karaoulanis, MBA, MsEng is currently working in the banking sector in Greece. He has an MBA degree in Industrial Management and Economics form Blekinge Institute of Technology Sweden and a MSc in Engineering from Aristotle University of Thessaloniki. He is very experienced after 25 years of working in several industries like engineering, banking, retail and consulting. He is a Linked In blogger with many managerial posts. 